\title{
"OH CLARO HONOR DEL LÍQUIDO ELEMENTO», DE LUIS DE GÓNGORA, Y LA TRADICIÓN TRADUCIDA
}

\author{
Andrés Sánchez Robayna \\ Universidad de La Laguna \\ asrobayn@ull.edu.es
}

Para Bel, que también traducia

con nosotros, en memoria

\section{RESUMEN}

Este artículo presenta algunos ejemplos de traducción de poemas, en cuanto creación literaria, como portadora de la tradición poética.

PALABRAS Clave: Góngora, traducción, tradición, imitatio, amulatio.

\section{ABSTRACT}

«"Oh claro honor del líquido elemento”, by Luis de Góngora, and the translated tradition». This paper shows some examples of translated poems, as literary creation, that carry the whole poetic tradition with them.

KEY WORDS: Góngora, translation, tradition, imitatio, amulatio.

He aquí, en primer lugar, el soneto gongorino, escrito en 1582:

Oh claro honor del líquido elemento, dulce arroyuelo de corriente plata cuya agua entre la hierba se dilata con regalado son, con paso lento:

pues la por quien helar y arder me siento (mientras en ti se mira) Amor retrata de su rostro la nieve y la escarlata en tu tranquilo y blando movimiento,

vete como te vas, no dejes floja la undosa rienda al cristalino freno con que gobiernas tu veloz corriente,

que no es bien que confusamente acoja tanta belleza en su profundo seno el gran señor del húmido tridente ${ }^{1}$. 
En otra ocasión me he ocupado de este soneto como poema traducido². El texto de origen es este soneto de Bernardo Tasso:

O puro, o dolce, o fiumicel d'argento, più ricco assai ch'Ermo, Pattolo, o Tago, che vai al tuo cammin lucente e vago fra le sponde di gemme a passo lento;

o primo onor del liquido elemento, conserva integra quella bella immago, di cui non pur quest'occhi infermi appago, ma pasco di dolc'esca il mio tormento.

Qualora in te si specchia, e ne le chiare e lucid'onde tue, si lava il volto colei ch'arder potrebbe orsi e serpenti;

ferma il tuo corso; e tutto in te raccolto condensa i liquor tuoi caldi ed ardenti per non portar tanta ricchezza al mare ${ }^{3}$.

Traducción sui generis, ciertamente — vista con la perspectiva de hoypero poseedora de todas las peculiaridades que esa modalidad literaria presentaba a fines del siglo XVI, es decir, con libertades o particulares licencias respecto a lo que podemos llamar — siempre desde el punto de vista actual— texto «original» o «de partida».

Las cosas, por supuesto, eran percibidas de manera muy distinta en los tiempos de Góngora. Este, como todos los autores de los siglos XVI y XVII, no hacía tales distinciones en el plano de la escritura poética, puesto que, según el principio de la imitatio auctoris, toda escritura podía generar, en mayor o menor grado, una nueva escritura, un nuevo «original». En otras palabras: todo texto podía - y hasta debía - apoyarse de un modo u otro en un texto anterior o, para ser más exactos, en textos anteriores, según la doctrina de la imitación compuesta o «mixta», que Petrarca había difundido para toda la poesía de la época basándose en la conocida imagen de la abeja que liba en flores múltiples para elaborar su propio néctar, una imagen que — haciendo honor a su significado— había sido ya propuesta previa-

${ }^{1}$ Luis de Góngora, Obras completas, I, ed. Antonio Carreira, Madrid, Biblioteca Castro, 2000 , p. 22.

2 Véase mi artículo «Poesía y traducción: un soneto de Góngora», Cuadernos Hispanoamericanos, núm. 777 (marzo 2015), pp. 129-135. Puede consultarse en línea.

${ }^{3}$ Bernardo Tasso, Rime, II, ed. Domenico Chiodo, Turín, Edizioni Res, 1995, p. 73. 
mente por Horacio y Lucrecio, y cuya más remota referencia se halla tal vez en Aristófanes.

En el principio de la imitatio — apunta Carmen Codoñer en un sugestivo artículo- «se percibe una gradación que va de la simple inspiración en un "motivo" existente en el original, a la adopción del poema, con traducción parcial del mismo, como punto de apoyo al libre poetizar $»^{4}$. Aquí es donde interviene la modalidad de la emulatio, un paso más allá de la imitación, que reanima o reaviva el «original» y que representa, por tanto, una relación distinta y singular con el modelo. No hay ya una pasividad repetitiva, centrada en la simple reproducción, sino un gesto de libertad creadora que, sin perder de vista nunca el modelo mismo, trata de superarlo, de rebasarlo.

Resulta innecesario, sin duda, subrayar que es esto lo que explica la intrincada trama textual que constituye la literatura de Occidente, desde los mismos clásicos griegos y latinos hasta los poetas, prosistas y dramaturgos del siglo XVIII, con cumbres como Cervantes y Shakespeare, inexplicables sin esta doctrina que aseguraba la continuidad o la perennidad de una cultura a través tanto de las diferentes emulaciones creadoras (dentro de la propia lengua o partiendo de otra) como de las influencias recíprocas de sus literaturas. En el centro mismo de esa trama parece estar planteada siempre la invitación a descubrir en todo texto, como parte inseparable de su sentido, los textos que lo alimentan en mayor o menor medida, hasta llegar a los trasfondos compartidos por distintas literaturas.

$\mathrm{El}$ soneto de Góngora "Oh claro honor del líquido elemento» traduce un poema en lengua italiana de Bernardo Tasso, «O puro, o dolce, o fiumicel d'argento», pero este poema se inspiraba a su vez, en cuanto al motivo del agua como espejo — según subraya oportunamente Georges Güntert ${ }^{5}$ —, en otro poema escrito en la misma lengua por Lorenzo de' Medici (1449-1492):

Chiare acque, io sento il vostro mormorio

che sol della donna mia il nome dice:

credo, poi ch'Amor fe'vi sì felice,

che fussi specchio al suo bel viso e pio.

${ }^{4}$ Carmen Codoñer, «Fray Luis: “interpretación”, traducción poética e imitatio», Criticón, 61 (1994), p. 34.

5 «Simili riflessi di immagini femminili nelle acque sono frequenti già nell'opera [de] Bernardo Tasso, in componimenti quali "Chiare fontane" e "O puro, o dolce, fiumicel d'argento". Esiste invero un precedente ancora più lontano nel sonetto "Chiare acque" di Lorenzo de' Medici, il quale oppone la fugacità del riflesso nell'acqua, che non può ritenere l'immagine dell'amata, alla più costante memoria dell'amante»; Georges Güntert, «Sete di simmetria: i poeti del primo Seicento di fronte alla varietà del mondo", en M. Burkhardt, A. Plattner, A. Schorderet, Parallelismen: Literaturund kulturwissenschaftliche Beiträge zu Ehren von Peter Fröhlicher, Tübingen, 2009, p. 100. 
La bella imagin sua da voi partìo, perché vostra natura vel disdice; solo il bel nome a voi ricordar lice, né vuole Amor che lo senta altri ch'io.

Quanto più fûro o fortunati o saggi che voi, chiare acque, gli occhi miei, quel giorno che fûrno prima specchio al suo bel volto,

servando sempre in loro i santi raggi.

Né veggon altro poi mirando intorno, né gliel cela ombra, né dal sol gli è tolto ${ }^{6}$.

Es evidente pues que, sabiéndolo o no, Góngora estaba traduciendo también a Lorenzo de' Medici en cuanto a la imagen central del agua como espejo (aunque los paralelismos no vayan mucho más allá), si por «traducir» entendemos algo más que un estricto vertido de palabras de una lengua a otra, concepción «libre» que era precisamente la que sostenían Góngora y los poetas de su tiempo; estaba — dicho sea con otros términos - trasladando de manera indirecta las imágenes y los valores de una tradición poética, a los que de ese modo daba continuidad. Y lo hacía no mediante la repetición mecánica de esas imágenes y valores literarios, sino con poderosos instrumentos creadores, tratando de competir con su modelo y rebasarlo.

En los estudios gongorinos, por desgracia, no han sido tenidas en cuenta hasta hoy sino muy escasamente las traducciones realizadas en su tiempo de la obra del poeta cordobés, traducciones a las que aquí deseamos conceder la atención que merecen, en la medida en que subrayan tanto la importancia de esa obra en la poesía europea de la época (y también en la América hispana, claro está) como su recepción y su influjo en los sistemas literarios continentales. Muy poco conocida, por ejemplo, es la traducción del soneto que nos ocupa, realizada por Sir Richard Fanshawe (1608-1666), poeta y diplomático que llegó a ser embajador en Madrid, donde murió, y que tradujo igualmente Il pastor Fido de Guarini (The Faithfull Shepherd, 1647), algunas obras de Horacio (Selected Parts of Horace, Prince of Lyricks, 1652) y el gran poema de Camoens (The Lusiads, 1655). Este es el fruto de su esfuerzo:

\section{A RIVER}

Thou clearer honour of the Christall Mayne,

Sweet Rivulet, compos'd of liquid plate,

Whose waters glide through this enamell'd plaine

With sound harmonious, with stately gate;

${ }^{6}$ Lorenzo de’ Medici, Opere, a cura di Attilio Simioni, vol. I, Bari, Editori Laterza, 1914, p. 72. 
Since shee is standing on thy happy brimme

Who both enflamed and congeales my blood,

Whilst Love with admirable skill doth limme

Her portraict on thy smooth and quiet flood;

Move on thus Gently still, and doe not slacke

The waving reynes unto the foaming bit

With which thou now art pleased to pull backe

Thy headstrong Current: For it is not fit

Neptune with all the treasures he doth hold

Should so much beauty in his Armes infold?

Como puede verse, Fanshawe no fue tan lejos con don Luis como este con Tasso. Su traducción, fuertemente apegada al modelo (aunque muy meritoria, por otra parte, como ejercicio de adaptación), se preocupó ante todo por naturalizar en lengua inglesa el poema, sustituyendo el soneto italiano (dos cuartetos y dos tercetos, ABBA-ABBA-CDE-CDE) por el isabelino (tres serventesios y un pareado, ABAB-CDCD-EFEF-GG), como hizo con otros sonetos del poeta cordobés ("Con diferencia tal, con gracia tanta», «Pálida restituye a su elemento», «En el cristal de tu divina mano», etc. ${ }^{8}$ ) y traducirlo casi literalmente, si bien esa literalidad suponía deshacer el artificioso hipérbaton del segundo cuarteto, modificar alguna metáfora («líquido elemento» pasa a ser "Christall Mayne», aunque «líquido» es trasladado al segundo verso: «liquid plate») y sacrificar una sugerente perífrasis alusiva por una mención directa del dios Neptuno. Por lo demás, Fanshawe sale airoso de la empresa y consigue una versión hábil de un poema cuyo modelo italiano no es seguro que conociera.

Esta es la cuestión que aquí nos interesa. En relación con las fuentes del texto, tanto si el traductor es consciente de ellas como si no, todo poema, lo mismo si se traslada de manera muy cercana a la letra que si se pretende superar el texto de origen, traduce una tradición. Fanshawe no conoció tal vez el poema de Tasso, y menos aún quizá el de Lorenzo de’ Medici, pero, en la medida en que el poema

${ }^{7}$ Oro español. Traducciones inglesas de poesía española de los siglos dieciséis y diecisiete, ed. bilingüe y selección de Glyn Pursglove, Valladolid, Universidad de Valladolid, 2014, p. 135. Véase mi comentario sobre este libro, “"Oro español”: más sobre literatura comparada y traducción literaria», en Boletín del Taller de Traducción Literaria de la Universidad de La Laguna, 17 (otoño de 2015), p. 1, en el que apunto algunas cuestiones aquí desarrolladas.

${ }^{8}$ El caso de "La dulce boca que a gustar convida» ("That lovelie mouth, which doth to taste invite»), inspirado, como es sabido, en otro de Torquato Tasso ("Quel labbro che le rose han colorito»), plantea la misma situación que «O claro honor del líquido elemento», es decir: Fanshawe traducía también al poeta italiano. 
que traduce absorbe esos otros textos, su traducción los incluye. La doctrina de la imitatio es fuertemente solidaria de la idea de tradición como traslación o traducción de valores literarios. En otras palabras: una de las maneras que la tradición tiene de perpetuarse, de plasmar sus valores, es justamente a través esa variedad de la imitación que representa la amulatio a través del «libre poetizar» de la traducción. No siempre, sin embargo, se podía estar a la altura de esa tradición, sobre todo en los casos de extrema dificultad: Fanshawe se atrevió igualmente a traducir cinco fragmentos de la Fábula de Polifemo y Galatea (rematadas con un resignado «Imperfect»), así como con un fragmento de las Soledades, proyecto que hubo de abandonar no sin dejar anotado, finalmente, "—difficiles valete nugae».

Lo dicho no sería válido únicamente para los días de Góngora y de Fanshawe, sino también para épocas posteriores, aunque en estas cobra un sentido distinto, porque la imitatio dejó de operar como doctrina y como práctica literaria de obligado cumplimiento a partir de finales del siglo XVIII con la aparición de la poética romántica. Aparecen, a partir del Romanticismo, formas diferentes de dar continuidad a la tradición mediante la traducción, especialmente a través del trabajo realizado por poetas traductores, para quienes traducir es otra manera de crear, de «recrear» o reescribir el texto de partida y darle una nueva vida en la lengua de llegada. Los ejemplos — de Hölderlin a Eliot, de Baudelaire a Ungaretti- resultan incontables.

En 1948 publicaba Giuseppe Ungaretti un volumen de traducciones titulado Da Góngora e da Mallarmé, en el que recogía sus versiones de veinte sonetos gongorinos, además de dos estrofas del Polifemo. El autor de L'allegria había empezado a traducir al poeta cordobés en 1932. El volumen de 1948 era en cierto modo la culminación de un esfuerzo tendente a explicitar tanto algunas raíces de su propia poética como el papel central de Mallarmé en el interior de la modernidad y su enlace con el espíritu barroco. Ungaretti nunca abandonó del todo la clave «hermética» en la que leyó siempre al poeta cordobés, nunca desplazó — escribe José Pascual Buxó"el sustrato de una primera lectura simbolista y metafísica de la poesía gongorina»"

Era otro modo de entender, y de reelaborar para su tiempo, la tradición recibida; era, para decirlo con otras palabras, su personal lectura de esa tradición. De ahí que la traducción fuera para Ungaretti un instrumento idóneo no solo para «recrear» obras que le importaban especialmente desde el punto de vista de la poética del «hermetismo» italiano, sino también una operación crítica.

Aunque de distinta manera, la traducción como portadora de tradición se cumple no menos en la versión de Giuseppe Ungaretti que en la de Sir Richard Fanshawe (como, antes, en la del propio Góngora respecto a Bernardo Tasso):

'José Pascual Buxó, Ungaretti y Góngora. Ensayo de literatura comparada, México, UNAM, 1978, p. 14. 


\section{A UN RUSCELLO}

Chiaro onore del liquido elemento, D'una corrente argentea rivo dolce La cui acqua si dilata e va tra l'erba Con un festoso suono e il passo lento,

Poiché a Lei per cui fuoco provo e gelo (Mentre si mira in te), ritratta Amore La neve e lo scarlatto del sembiante, Nel blando tuo tranquillo movimento

Va cauto, ottieni che l'ondosa briglia Con cui governi rapide correnti $\mathrm{Al}$ cristalino freno non s'allenti.

Dell'umido tridente il gran signore Bene non è che accolga in confusione Tanta bellezza nel suo seno fondo ${ }^{10}$.

Ungaretti mantiene hipérbatos, correlaciones y quiasmos (o los compensa, como en el caso del hipérbaton del segundo verso, que no existe en el texto gongorino, o el del último terceto, que parece hacerse eco de la violencia sintáctica de la segunda estrofa de partida), y al mismo tiempo se permite procedimientos inesperados, como mantener algunas rimas (elemento-lento-movimento), prescindir de otras (plata-dilata-retrata-escarlata, etc.) o crear alguna nueva (correnti-alenti).

Lo que aquí nos interesa, sin embargo, no es tanto examinar la técnica o el método de traducción seguido por Ungaretti (trabajo ya realizado en parte por Buxó en su citado libro, aunque no aborda este soneto) cuanto hacer notar que su versión italiana de «Oh claro honor del líquido elemento» supone igualmente una traducción de la tradición contenida en el poema gongorino. En la versión ungarettiana, continúa la imagen central (la del agua como espejo), pero pocas huellas léxicas y sintácticas quedan ya del soneto de Lorenzo de' Medici (apenas algún sustantivo, acqua, o adjetivo, chiaro) ni del soneto de Tasso: aunque algunas expresiones permanecen (onore del liquido elemento, passo lento), así como algunos adjetivos (dolce, chiare-chiaro) y algún giro, modificado (tanta ricchezza-tanta belleza), el poema «regresa» a la lengua italiana enteramente transformado, «recreado» como ha sido previamente por Góngora. Al traducir, Ungaretti, de hecho, reescribe una reescritura ${ }^{11}$.

${ }^{10}$ Giuseppe Ungaretti, Da Góngora e da Mallarmé, Milán, Mondadori, 1948, p. 29.

${ }^{11}$ La de Ungaretti no es la única traducción italiana del soneto. Véase la excelente versión de Giulia Poggi: "Chiaro onore del liquido elemento, / dolce ruscello che fuggi argentato, / che in mezzo all'erba l'acqua tua diffondi / con suono delicato e passo lento, // poiché colei per cui son fuoco e ghiaccio 
Los valores de la lengua poética de Góngora habían sido redescubiertos por Ungaretti después de que la lírica europea conociera la fuerte impronta del simbolismo. "En la agudeza, Góngora había introducido un ímpetu emotivo tal que la hizo aparecer también a los poetas europeos del segundo cuarto del Novecientos como un recurso lírico novísimo" ${ }^{12}$, confiesa Ungaretti en su ensayo de 1951 "Góngora a la luz de hoy». Nada más coherente por parte de Ungaretti que recrear o reescribir en italiano ese «impulso emotivo" de la agudeza barroca tal y como era practicada por Góngora y reintroducirla en la lengua de llegada.

La traducción actuaba, en este contexto, como la recuperación para el presente de una obra capaz de intervenir en el proceso evolutivo de la lírica europea postsimbolista. La poesía de Góngora como una fuerza revitalizadora fue, pues, un elemento importante en ese proyecto de renovación. Esto nos lleva a ver en la traducción literaria algo más que el sentido que atribuimos normalmente a esa práctica, esto es, un traslado o trasposición más o menos afortunada de unas formas y contenidos determinados. «La traducción —escribe Marina Guglielmi- produce un efecto extraordinario: el rejuvenecimiento, la renovación, la revitalización y el renacimiento de las literaturas» ${ }^{13}$. Hay en la traducción, en algunos casos, una renovación de la tradición recibida, una propuesta de reactivar valores literarios concretos que pueden dinamizar el presente y abrirlo a nuevas posibilidades creadoras. La conclusión de Guglielmi no puede ser, en este sentido, más explícita: hoy «se reconoce [...] la función cultural que desempeña la traducción, entendida como proceso, como acto dinámico que conlleva una serie de consecuencias y que supera definitivamente la perspectiva que la veía simplemente como un producto, el resultado del paso (de un texto) desde una lengua de partida a una lengua de llegada $»^{14}$.

La traducción representa, pues, un modo privilegiado de encarar la tradición, de asegurar su continuidad y, en algunos casos, de darle un nuevo sentido. Al traducir, ya Góngora, en su época, hizo ambas cosas: afianzar el italianismo, de una parte, y renovarlo, de otro. El soneto de Góngora «Oh claro honor del líquido elemento" imitaba libremente — traducía, en el sentido de la época- el soneto de

/ - mentre si mira in te- ritrae Amore, / e del suo volto scarlatto e candore / nel tuo tranquillo e blando movimento, // vai cosí como vai; non allentare / l'ondosa briglia al cristallino freno / che regge la tua indómita corrente, // ché non è bene che confusa accolga / tanta belleza nel suo fondo seno / il gran Sire dall'umido tridente.» (Luis de Góngora, Sonetti, a cura di Giulia Poggi, Roma, Salerno Editrice, 1997, p. 155.)

${ }^{12}$ «... nella argutezza, il Góngora aveva compresso un impeto emotivo di grado tale da farla apparire anche a poeti europei del secondo quarto del Novecento mezzo lirico nuovissimo» («Góngora al lume d'oggi», en G. Ungaretti, Vita d'un uomo. Saggi e interventi, a cura di M. Diacono e L. Rebay, Milán, Mondadori, 1974, p. 530).

${ }^{13}$ Marina Guglielmi, «La traducción literaria», en Armando Gnisci, ed., Introducción a la literatura comparada, Barcelona, Crítica, 2002, p. 316.

${ }^{14}$ Ibíd., p. 292. 
Bernardo Tasso "O puro, o dolce, o fiumicel d'argento...». Pero el soneto de Bernardo Tasso estaba inspirado a su vez —en parte, pero en su imagen central — en otro soneto de Lorenzo de' Medici, "Chiar' acque i sento il vostro mormorio...". Cuando Richard Fanshawe, en el siglo XVII, y Giuseppe Ungaretti, en el XX, traducen el soneto gongorino, están — cada uno a su manera — traduciendo la tradición, es decir, están haciendo en sus lenguas respectivas ese encaramiento del legado literario recibido, adoptando una postura frente a él a través de la traducción. Góngora no había hecho algo distinto: cuando traducía a Tasso, no solo estaba traduciendo a este sino que también estaba asumiendo - $\mathrm{y}$ «trasladando»— toda una tradición poética. Cada uno de esos poemas, cuando nosotros los leemos, no hace sino situarnos frontalmente ante la tradición traducida. 
